\title{
A Proposed Model for an Optimal Mentoring Environment for Medical Residents: A Literature Review
}

Orin C. Davis, MA, and Jeanne Nakamura, PhD

\section{Abstract}

\section{Purpose}

To develop a model of the optimal mentoring environment for medical residents. The authors propose that such an environment is a function of a relationship that rests upon a set of interactional foundations that allow a protégé to capitalize on the strengths of the mentor, and it facilitates behaviors that will enable the protégé to develop and internalize the requisite knowledge, skills, and attitudes (KSAs) as fully as possible.

\section{Method}

The authors searched the literature using Web of Science and Google Scholar in 2007-2008 to identify articles addressing the mentoring process and the context in which it occurs (mentoring environment), and the effect both have on KSA development. The authors distilled the attributes of a good mentor that were consistent across the 20 papers that met inclusion criteria and described good mentoring of residents or curricula for training mentors or residents.

\section{Results}

The authors identified six interactional foundations that underlie the optimal mentoring relationship: emotional safety, support, protégé-centeredness, informality, responsiveness, and respect. These foundations enable protégés to engage in four key developmental behaviors: exercising independence, reflecting, extrapolating, and synthesizing.

\section{Conclusions}

This model identifies mentoring practices that empower protégés to engage in developmental behaviors that will help them become the best physicians possible. Educators may use this model to develop training tools to teach attendings how to create an optimal mentoring environment. Researchers can use the model to help guide their future investigations of mentoring in medicine.

Acad Med. 2010; 85:1060-1066. ne of the key recommendations of the American Medical Association's 2007 Initiative to Transform Medical Education ${ }^{1}$ was to "ensure that the learning environment throughout the medical education continuum is conducive to the development of appropriate attitudes, behaviors and values, as well as knowledge and skills." During residency, a crucial period in the "educational continuum," the development process is largely facilitated by an outcome-driven mentoring relationship between an attending physician and a resident. Although the literature addresses residency training in general, researchers have not identified the characteristics that distinguish a good mentor, who effects a positive outcome in a resident, from a good mentoring environment, the

Mr. Davis is a doctoral candidate, School of Behavioral and Organizational Sciences, Claremont Graduate University, Claremont, California.

Dr. Nakamura is assistant professor, School of Behavioral and Organizational Sciences, Claremont Graduate University, Claremont, California.

Correspondence should be addressed to Mr. Davis, Quality of Life Research Center, Claremont Graduate University, 1227 N. Dartmouth Ave., Claremont, CA 91711; telephone: (909) 607-3901; fax: (909) 6073903; e-mail: Orin.Davis@cgu.edu. atmosphere in which the mentoring process activates the resident's development and internalization of the requisite knowledge, skills, and attitudes (KSAs) to the fullest extent possible (i.e., the maximal outcome).

Although it seems likely that a good mentor would create a good mentoring environment, there is an important distinction between a relationship that is good for a protégé and one that is optimal. In a good mentoring relationship, a protégé might not be able to capitalize on all of the mentor's strengths and, consequently, might not achieve the maximal outcome. Thus, we propose that the optimal mentoring environment is a function of a relationship that (1) rests on a set of interactional foundations (the fundamental elements of the mentorprotégé relationship that inform their interactions) that allow a protégé to capitalize on his or her mentor's strengths and (2) enables a protégé to engage in behaviors that foster the development and growth that will yield a maximal outcome. This raises two questions: Which aspects of the relationship allow a protégé to capitalize fully on the mentoring relationship?
Which developmental behaviors should the mentoring relationship enable the protégé to perform in order to achieve a maximal outcome?

When designing any environment, an architect must consider two aspects: what it will be made of, and what it must have space for. Consider a baseball stadium. Its stands and field are made of materials such as dirt, grass or turf, concrete, metal, and glass. The stadium must have space for key game-related activities to occur, such as players sitting while their teammates bat, pitchers warming up, and fans watching and cheering. Applying this analogy to the abstract mentoring environment, the "stadium materials" are the building blocks (interactional foundations) that underlie the optimal mentoring relationship, such as trust and support, and the "game-related activities" are the developmental behaviors that the relationship enables the resident to pursue, like reflecting and synthesizing. The optimal mentoring environment may differ between specialties and hospitals, but there remains a core set of attributes that ought to be inherent in every optimal mentoring environment, just as there is in every baseball stadium. 
Relatively little is known about what makes mentoring relationships in residency training effective. ${ }^{2} \mathrm{We}$ conducted a review of the literature on good mentoring in residency training to develop a model of the optimal mentoring environment that can guide future inquiries. Building on previously developed frameworks and methods, ${ }^{3-5}$ we distilled a set of recurring attributes from a review of the literature. In this article, we present our model and offer a few examples of implementation.

\section{Method}

\section{Literature search}

Between fall 2007 and spring 2008, we used two online search engines to find papers on good mentoring in residency training: Web of Science and Google Scholar. We performed a topic search for literature published within the previous 15 years in the Web of Science database, searching for permutations of the root mentor. We searched within these results for permutations of the root resident or residency, leading to 792 articles, which we combined with additional articles identified via a second search that encompassed three topic searches in the Web of Science database: attending AND resident $\mathrm{AND}$ relationships; attending AND resident AND mentor ${ }^{*}$; and attending AND resident AND apprentic ${ }^{\star}$. The first author (O.D.) reviewed the combined results for relevance by year, title, and abstract, yielding 18 articles. Finally, we conducted a search in Google Scholar using targeted search terms (resident AND attending AND relationship) to find any papers we missed in the Web of Science searches. The first author reviewed the first 1,000 hits for relevance by year, title, and abstract, yielding 12 articles.

\section{Article selection process}

Thirty articles (18 from Web of Science, 12 from Google Scholar) met our inclusion criteria: They focused on the constructs of interest, which were the mentoring process, the context in which it occurs (mentoring environment), and the effects both have on residents' development and acquisition of the requisite KSAs, particularly with respect to the fundamental elements of the mentoring relationship and the developmental behaviors they enable. The first author reviewed the 30 articles and excluded 10 that focused on mentoring with respect to demographics/ career choices or that were too limited in their coverage of the specific processes involved in mentoring or of how to be/ train a good mentor (e.g., Bligh $\left.{ }^{6}\right)$. We used the remaining 20 articles ( 11 from Web of Science, 9 from Google Scholar) to construct our model of the optimal mentoring environment, which incorporates the attributes mentioned at least five times across the reviewed literature. We divided the 20 articles into two categories: (1) articles that provided descriptions of, and recommendations for, good mentoring practices and (2) those that described curricula, which were limited to programs for training senior faculty to be mentors and residency curricula that included guidelines for implementation (see Table 1).

We examined the guidelines for mentor training (e.g., how to teach and communicate with residents) both because the teacher-student dynamic is a part of the mentor-protégé relationship and because the techniques of good teaching should be applied to instructing residents. ${ }^{3,7}$ Looking specifically at the implementation of curricula allowed us to investigate the means for creating a maximally effective learning environment, including the developmental behaviors that the curricula recommend and the aspects of the teacher-student (mentor-protégé) relationship that enable those behaviors. ${ }^{8}$ Reports on curricula are concerned with objectives, whereas the articles that examine mentoring relationships highlight successful mentoring and provide reallife examples of how the interactional foundations allow protégés to engage in developmental behaviors.

Of the 20 articles, 6 were reviews of empirical literature and 14 were empirical papers using quantitative and/ or qualitative methods. Both authors reviewed 5 of the 20 articles and identified the interactional foundations and developmental behaviors (see Results) with good interrater reliability $(\kappa=0.81)$. The tabulation reported was conducted by the first author, who conferred with the second author (J.N.) as needed.

\section{Results}

We found that optimal mentoring environments are a function of mentorprotégé relationships rooted in six interactional foundations: emotional safety, support, protégé-centeredness, informality, responsiveness, and respect. These foundations enable protégés to engage in four developmental behaviors: exercising independence, reflecting, extrapolating, and synthesizing (Table 2).

\section{Interactional foundations}

We identified six interactional foundations (Table 2) that appear with high frequency across the literature that covers mentoring in the context of residency and curricula for training residents or attendings: emotional safety (17 of 20 articles), responsiveness (15), support (15), protégé-centeredness (11), respect (10), and informality (6).

Emotional safety. A hallmark of all but one of the curricula is creating emotional safety by maintaining a nonthreatening environment with manageable pressure in which protégés can apply themselves fully to the learning process and maximize their development. ${ }^{4,8}$ Part of residents' development is making mistakes, but because the cost of a mistake can be grave, residents are under enormous amounts of pressure. Thus, it is important for attendings-their mentors - to manage that pressure and refrain from adding more unnecessarily. Mentors should also alleviate residents' fears that making a mistake can lead to overly harsh repercussions or humiliation. ${ }^{9}$ Behavioral recommendations in the literature for accomplishing this include giving residents more time to think, act, and respond to inquiries, ${ }^{3}$ not poking fun at residents' theories/ ideas, eschewing curt or forceful admonishment, ${ }^{10,11}$ tolerating expressions of emotion (e.g., frustration and anxiety), ${ }^{7}$ and refraining from harsh or gratuitous criticism. ${ }^{12}$

Several articles suggest personal characteristics of mentors that facilitate emotional safety, including having a calm temperament, ${ }^{13}$ being patient, being nonjudgmental, ${ }^{12,14,15}$ and being easy to approach with questions or concerns. ${ }^{12,16}$ One of the other key ways to provide a safe environment is to engage residents in 
Mentoring

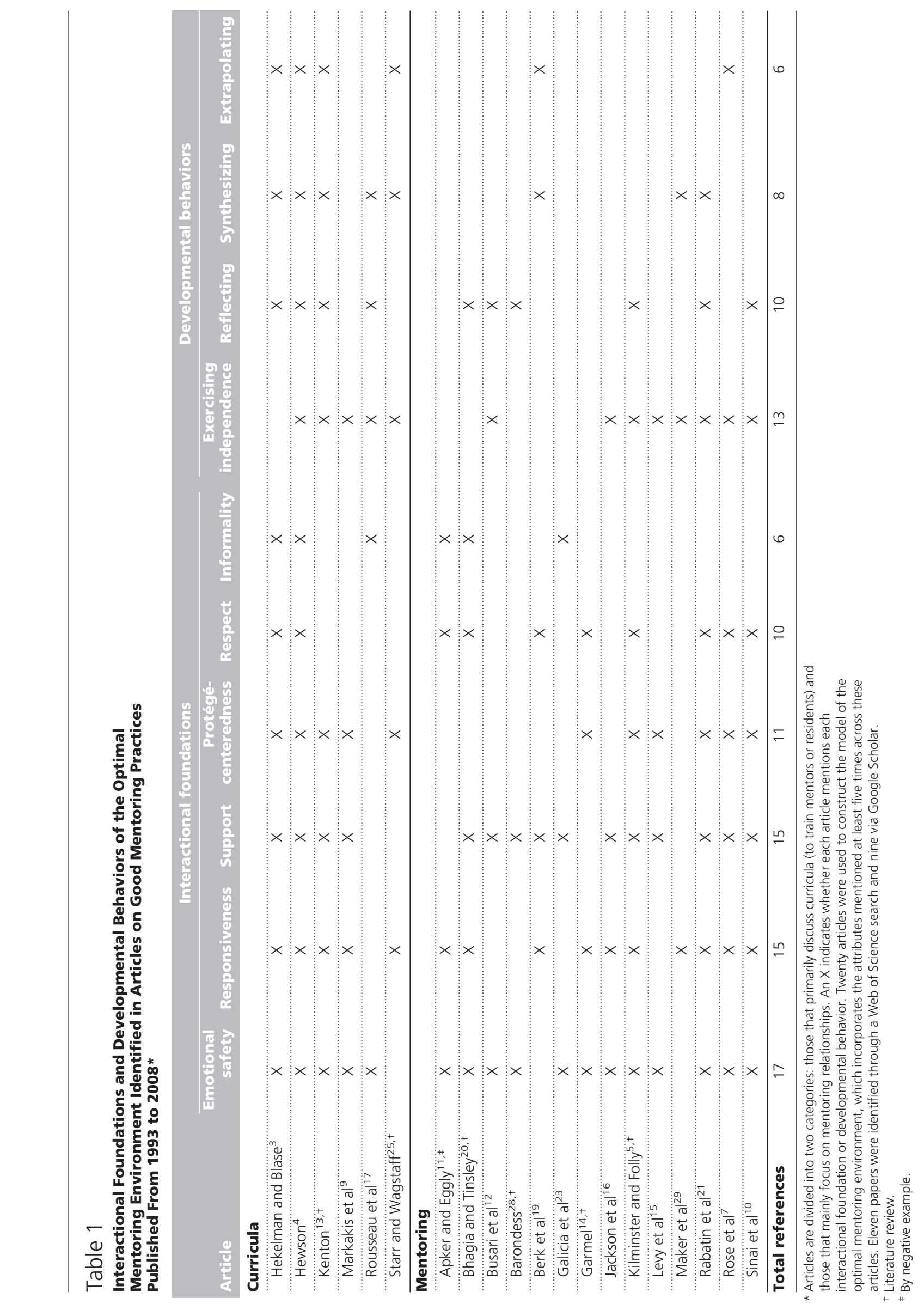

$\overline{1062}$

Academic Medicine, Vol. 85, No. 6 / June 2010

Copyright $\odot$ by the Association of American Medical Colleges. Unauthorized reproduction of this article is prohibited. 
Table 2

Examples of the Interactional Foundations and Developmental Behaviors Present in the Optimal Mentoring Environment*

Aspect of the optimal

mentoring environment

Examples

\section{Interactional \\ foundation}

\begin{tabular}{ll} 
Emotional safety & $\begin{array}{l}\text { - Mentor is nonjudgmental } \\
\text { - Mentor refrains from curt or forceful admonishment } \\
\text { - Mentor gives the resident time to think/act/respond }\end{array}$ \\
\hline Responsiveness (feedback) & - Mentor makes time for the resident \\
- Mentor presents ongoing and retrospective feedback & - Mentor conveys empathy \\
- Mentor protects the resident
\end{tabular}

\section{Developmental}

behavior

Exercising independence

- Resident takes a lead role in procedures

- Resident repeats procedures with increasingly reduced supervision

Reflecting - Resident thinks about how to improve future actions in light of prior performance

- Resident develops self-awareness

Synthesizing - Resident integrates multiple areas of medicine

- Resident combines clinical experience and classroom knowledge

Extrapolating

- Resident uses an existing skill in a different way

- Resident applies information presented at rounds or colloquia to new patients

\footnotetext{
* Citations for the interactional foundations and developmental behaviors are provided in Table 1.
}

learning activities that do not have the pressures of clinical responsibilities, such as a rotation spent observing and learning ${ }^{17}$ or using a simulator. ${ }^{18}$ Using a simulator permits residents to make mistakes and experiment with new ideas and procedures without having to worry about harming patients. ${ }^{18}$

Responsiveness. The second interactional foundation is responsiveness, or making time for the protégé and providing clear and honest feedback in a caring and constructive manner. ${ }^{7,14,19}$ Some authors describe a "generous" commitment of time and energy on a regular and ongoing basis, ${ }^{14,20}$ while another stresses overall availability. ${ }^{7}$ Likewise, some recommend that feedback, in addition to being caring and constructive, should be frequent, detailed/explicit, ${ }^{10,21}$ nonpersonal (i.e., objective), both formative and summative (ongoing and retrospective), and presented as close to the relevant activities as possible, ${ }^{13,19}$ and that it should emphasize items that the resident needs to learn. ${ }^{3}$

Support. The optimal mentoring environment features the mentor's support for the resident, which involves both supportive actions and building of psychological resources. In general, the mentor's support enables the resident to deal with the challenges and emotional issues that arise during residency, $4,22,23$ facilitates the resident's ability to function and develop, and keeps the resident from "feel[ing] alone." 10 Mentor-initiated supportive actions include providing trust, conveying empathy, protecting the protégé, $3,8,9,16,24$ and providing encouragement. ${ }^{19,20}$ Resource building cultivates in residents positive psychological resources_-such as self- confidence and self-efficacy, ${ }^{3,5}$ motivation, ${ }^{16,19,20}$ and enthusiasm and a positive attitude ${ }^{7}$ - that support the undertaking of developmental behaviors. For example, mentors can cultivate such resources in their protégés by maintaining a positive attitude themselves, ${ }^{7}$ or they can tailor feedback in a way that preserves self-confidence and affirms self-efficacy. ${ }^{5}$ As one attending suggests, "successful mentoring is less distinguished by innate personality than by supportive behaviors." 21

Protégé-centeredness. The optimal mentoring environment should tailor teaching, advising, and mentoring to meet the needs of the protégé. Protégécenteredness takes the form of individualized instruction, ${ }^{25}$ tailoring teaching to what the student does and does not know, ${ }^{10}$ or teaching in the modality preferred by the student (e.g., spoken instructions for verbal learners). ${ }^{7,13}$ It can also involve addressing the broader, personal needs of each student. ${ }^{14}$ Mentors may also give each student the opportunity to ask questions during activities ${ }^{8}$ and help their protégés identify and achieve specific personal goals. 7,15

Respect. It is important for there to be respect between the resident and the attending. In an optimal mentoring environment, attendings regard their protégés as future colleagues and treat them fairly and appropriately. ${ }^{3}$ Mentors should respect residents' goals ${ }^{20}$ and circumstances, ${ }^{3}$ as well as their uniqueness, ideas, work, and contributions. ${ }^{4,10,11,19}$ Although many authors seem to take for granted the respect a protégé has for a mentor, some specifically note that a good mentor is both respectful and respected. ${ }^{7,14}$

Informality. The optimal mentoring environment allows for informality through the collegiality and friendliness that arise when part of the mentoring relationship occurs outside official channels. The literature suggests that both the matching of mentor and protégé and the context in which mentoring occurs should be informal. Some authors suggest that the relationship should be initiated by the mentor and protégé, as is the case when the resident chooses his or her own mentor, ${ }^{23}$ rather than being assigned and regulated by a formal 
mentoring program. ${ }^{14,26,27}$ Others consider informal to mean occurring outside the formal mentoring context, ${ }^{17}$ such as mentoring interactions that occur away from [formal] clinical settings or socializing with a mentor outside the supervisor-subordinate relationship. ${ }^{4}$

\section{Developmental behaviors}

The optimal mentoring environment enables a set of developmental behaviors that foster growth and development in residents such that residents acquire and internalize the KSAs necessary to be a maximally effective physician. We identified four developmental behaviors (Table 2) that appeared with a high frequency in the literature: exercising independence (13 of 20 articles), reflecting (10), synthesizing (8), and extrapolating (6).

Exercising independence. Residents need opportunities to act independently with minimal direct supervision and to take leadership roles. One of the primary features of independence is acting autonomously at a level commensurate with ability and experience. ${ }^{17,21}$ An example is a teaching paradigm in which residents repeatedly perform procedures with increasing amounts of responsibility each time. ${ }^{13}$ A mentor may be able to encourage independence by using such an approach while remaining readily available for consultation ${ }^{12}$ to afford the resident the opportunity to work without direct supervision ${ }^{7}$ and to make his or her own mistakes. ${ }^{10}$ Exercising independence also means practicing leadership, such as by teaching juniors or taking a primary role in procedures, which allows the protégé to practice skills, express attitudes, apply knowledge, ${ }^{17,21}$ and construct an independent professional identity. ${ }^{16}$

\section{Reflecting. The optimal mentoring} environment encourages the resident to reflect on past actions, experiences, and behaviors and then consider how they may apply in future contexts and use them as a springboard for improving performance. The literature considers reflection in a variety of contexts, including reflecting on clinical knowledge and events, ${ }^{12}$ developing selfawareness, ${ }^{4,13,28}$ and learning from mistakes. ${ }^{10}$ A pilot program at Université Laval (Laval, Quebec, Canada) proposes several methodologies to encourage reflection, including essay writing and small-group discussions. ${ }^{17}$

Synthesizing and extrapolating. Synthesizing and extrapolating are both key developmental behaviors that reflect the resident's evolution into a full-fledged physician. Synthesizing integrates established KSAs with each other or with new KSAs, thereby increasing the depth and/or strength of both. Extrapolating involves applying KSAs to novel contexts, which results in the resident's developing new KSAs or improving established KSAs. One of the primary examples of synthesizing is when a resident combines KSAs gained from didactic teaching with those gained from clinical practice. ${ }^{29}$ Another is integrating laboratory-based surgical training with operating room experience. ${ }^{25}$ The pilot program at Université Laval includes a component involving synthesis of clinical practice, observation, and even discussions with nonsupervising faculty. ${ }^{17}$ Other authors recommend that attendings provide residents with challenges in order to stimulate extrapolation. ${ }^{8,18,19}$ Another author combines both developmental behaviors by suggesting that attendings ask extrapolatory questions that require synthesis. ${ }^{3}$

\section{Discussion}

\section{Interactional foundations enable developmental behaviors}

Some authors drew explicit connections between interactional foundations and developmental behaviors. Here, we highlight some of these connections and hypothesize about additional connections that may exist. For example, consider the developmental behaviors of synthesizing and extrapolating, which can be promoted using protégé-centered exercises that are tailored to the resident. ${ }^{4}$ When these exercises are presented in an emotionally safe and supportive environment, the resident may have the self-confidence to try extending his or her knowledge despite the many opportunities for error inherent in novel contexts. If the mentoring relationship is informal, collegiality can foster open dialogue between the resident and attending, and the attending's provision of timely and constructive feedback can emphasize both the points that the resident needs to grasp and the areas that need additional work and development.
Similarly, there are connections between the developmental behavior of exercising independence and the interactional foundations. This behavior can be facilitated by the supportive mentor who both encourages the protégé to accept increasing levels of challenge relative to his or her individual talents, abilities, and experience (protégé-centeredness) and provides constructive feedback to guide his or her development (responsiveness). ${ }^{7}$ When the resident assumes a leadership role or acts independently, it helps the resident to know that his or her mentor will respect the temporary role (which can be facilitated by collegial informality) and that the mentor is confident in the protégé's ability to lead or act independently.

Further, a supportive and emotionally safe environment, in which the mentor conveys empathy, listens, and offers opportunities to reframe ideas, ${ }^{3}$ can enable the resident to feel more comfortable engaging in reflection. Removing conditions that cause selfconsciousness, fear of failure, and the like allows the resident to feel free to ask questions and receive criticism. ${ }^{4,22}$ Moreover, informality can augment emotional safety by moving the reflection process to a nonclinical setting, which facilitates reflecting from an "outsidelooking-in" perspective. When the protégé is confident of the mentor's respect and support, the protégé can feel comfortable being open and honest in the reflection process, secure in the knowledge that the mentor wants the protégé to succeed and that the mentor is trying to effect improvement for a future colleague rather than belittle a subordinate.

\section{Extending the current model}

Whereas some interactional foundations and key developmental behaviors receive considerable support in the literature (e.g., emotional safety), others are discussed less frequently. For instance, the literature tends to emphasize that mentors should respect protégés while taking for granted that protégés respect mentors. Because this article focuses on mentors' actions and behaviors, we made the same assumption. This example highlights a major direction for extending our model beyond how a mentor creates an optimal mentoring environment: considering the means by which a 
protégé actively makes the most of the optimal mentoring environment. ${ }^{30}$

There are a number of factors external to our model that could significantly affect its implementation. For this model to be most effective, residents and attendings should have some say in the mentorprotégé pairing and need to have sufficient opportunities to meet and to work together.

Another critical factor is mentor training. To use this model to develop the optimal mentoring environment, an implementation plan needs to be developed along with a curriculum, such that attendings learn both what an optimal mentoring environment is and how to create and maintain one. Ideally, such a curriculum would highlight the numerous ways that the mentoring relationship benefits the mentor as well as the field, which might serve to inspire or increase attendings' willingness to mentor. An added benefit may be the propagation of the willingness to mentor, insofar as protégés who receive good mentoring are more likely to become mentors themselves. ${ }^{31}$

\section{Creating an optimal mentoring}

environment requires, however, that the larger environment in which mentoring occurs is conducive to the cultivation of the mentor-protégé relationship. In a department or program with a high level of politics and/or hostility, for example, the mentor's protection might not be sufficient to maintain the crucial emotional safety component of the optimal mentoring environment. Strong leadership from a program director or department chair could help foster a culture that not only values cooperation and positive relationships but also specifically supports good mentoring and investing resources in mentor development.

Also, a number of key factors related to the optimal mentoring environment require additional consideration, particularly the frequency, duration, and quality of meetings (i.e., effective interactions with mentors). These factors should be measured so that they can be assessed with respect to protégé satisfaction and outcomes. Moreover, surveys should include demographic variables like gender, age, and ethnicity to evaluate how they affect success or failure in both the outcomes and the creation of the optimal mentoring environment. ${ }^{32}$

Likewise, there are methodological improvements that would result in richer data and deeper insight into the mechanisms and outcomes of the optimal mentoring environment. For example, one of the major flaws we found in a number of studies was that the data were primarily or entirely self-reported. ${ }^{5}$ Although the subjectivity and other weaknesses inherent in self-reports may suggest that such reports are not ideal, ${ }^{33,34}$ there are limited ways in which dyadic relationships can be assessed, and some researchers contend that using selfreports is perfectly acceptable. ${ }^{35}$ The experience of the mentoring relationship is subjective by definition, so it could be argued that one of the best ways to assess the relationship would be from the perspective of a dyad member. Ideally, though, this perspective should be compared with the perspectives of both the other party and a neutral observer, as well as with behavioral data, so as to triangulate on the most accurate assessment of the relationship that is possible. Most studies we reviewed failed to do this.

In addition, the studies that focus on evaluating mentoring programs or relationships are generally investigating which characteristics make good mentors, but the drawback of such studies lies in the fact that they usually use protégé satisfaction as the only metric of a "good mentor." Researchers cannot assume that a student who reports being highly satisfied is getting the most out of the mentoring relationship, or even that the mentor effects anything more than basic competence. ${ }^{8,36}$ Studies on mentoring should go beyond protégé satisfaction to include measures of the extent of the resident's development and internalization of the residency program's requisite KSAs as well as the resident's achievement of relevant individual development goals.

We hope that this model of the optimal mentoring environment will be tested across a range of specialties, programs, and demographics to refine it further and delineate additional boundaries. This research would ideally involve rigorous, mixed-method designs. For example, a future study could assess the extent to which the protégé experiences the six interactional foundations of the relationship and feels capable of engaging in the four developmental behaviors, the degree to which the protégé thinks that he or she is taking full advantage of the opportunities provided by the mentoring relationship, and how he or she does so. Future studies are needed to explore the mechanisms of the model, including how the interactional foundations enable the developmental behaviors (either alone or in concert), and which direct causal links exist among one or more interactional foundations and one or more developmental behaviors. Researchers could analyze the extent to which mentors can be trained to implement this model and the obstacles to implementation. Finally, the processes and outcomes of mentoring should be assessed both by professionals outside the mentoring relationship (e.g., another attending) and by patients to confirm that residents are indeed achieving the desired outcomes, such as developing and internalizing the residency program's requisite KSAs and the achievement of individual developmental goals.

The limitations in the methods of the studies we reviewed-including small sample size, self-report, disparate subject pools (e.g., coming from across areas of medicine, different stages of residency, different calibers of hospital), and problematic methodologies ${ }^{5,25}$ — are instructive for future researchers addressing the themes that we have identified. Despite these limitations, the consistency of the patterns we identified warrants additional investigation to elucidate further both the "stadium materials" used to create the interactional foundations of the optimal mentoring environment and the developmental behaviors ("game-related activities") that this environment allows. We hope that our model will promote the practice of good mentoring through interactions that empower protégés to engage proactively in the developmental behaviors that will help them become the best physicians possible.

Acknowledgments: The authors wish to thank Dr. Mihály Csikszentmihályi, Matt Jarman, Michelle Mason, Ia Ko, Roeuny Ros, Shamini Dias, and Dr. Michelle Bligh. 
Funding/Support: This study was funded by the Spencer Foundation.

Other disclosures: None.

Ethical approval: Not applicable.

\section{References}

1 American Medical Association, Council of Medical Education. Initiative to Transform Medical Education: Recommendations for Change in the System of Medical Education. Available at: www.ama-assn.org/ama1/pub/ upload/mm/16/itme_final_rpt.pdf. Accessed March 4, 2010.

2 Ramanan RA, Taylor WC, Davis RB, Phillips RS. Mentoring matters-Mentoring and career preparation in internal medicine residency training. J Gen Intern Med. 2006; 21:340-345.

3 Hekelman FP, Blase JR. Excellence in clinical teaching: The core of the mission. Acad Med. 1996;71:738-742.

4 Hewson MG. A theory-based faculty development program for clinicianeducators. Acad Med. 2000;75:498-501.

5 Kilminster SM, Folly BC. Effective supervision in clinical practice settings: A literature review. Med Educ. 2000;34:827840.

6 Bligh J. Mentoring: An invisible support network. Med Educ. 1999;33:2-3.

7 Rose GL, Rukstalis MR, Schuckit MA. Informal mentoring between faculty and medical students. Acad Med. 2005;80:344348.

8 Kram KE. Mentoring at Work. Glenview, Ill: Scott, Foresman and Company; 1985.

9 Markakis KM, Beckman HB, Suchman AL, Frankel RM. The path to professionalism: Cultivating humanistic values and attitudes in residency training. Acad Med. 2000;75:141150.

10 Sinai J, Tiberius RG, de Groot J, Brunet A, Voore P. Developing a training program to improve supervisor-resident relationships, step 1: Defining the types of issues. Teach Learn Med. 2001;13:80-85.

11 Apker J, Eggly S. Communicating professional identity in medical socialization: Considering the ideological discourse of morning report. Qual Health Res. 2004;14: 411-429.

12 Busari JO, Weggelaar NM, Knottnerus AC, Greidanus PM, Scherpbier A. How medical residents perceive the quality of supervision provided by attending doctors in the clinical setting. Med Educ. 2005;39:696-703.

13 Kenton K. How to teach and evaluate learners in the operating room. Obstet Gynecol Clin North Am. 2006;33:325-332.

14 Garmel GM. Mentoring medical students in academic emergency medicine. Acad Emerg Med. 2004;11:1351-1357.

15 Levy BD, Katz JT, Wolf MA, Sillman JS, Handin RI, Dzau VJ. An initiative in mentoring to promote residents' and faculty members' careers. Acad Med. 2004;79:845-850.

16 Jackson VA, Palepu A, Szalacha L, Caswell C, Carr PL, Inui T. "Having the right chemistry": A qualitative study of mentoring in academic medicine. Acad Med. 2003;78: $328-334$.

17 Rousseau A, Saucier D, Cote L. Introduction to core competencies in residency: A description of an intensive, integrated, multispecialty teaching program. Acad Med. 2007;82:563-568.

18 Gordon JA, Oriol NE, Cooper JB. Bringing good teaching cases "to life": A simulatorbased medical education service. Acad Med. 2004;79:23-27.

19 Berk RA, Berg J, Mortimer R, Walton-Moss $B$, Yeo TP. Measuring the effectiveness of faculty mentoring relationships. Acad Med. 2005;80:66-71.

20 Bhagia J, Tinsley JA. The mentoring partnership. Mayo Clin Proc. 2000;75:535537.

21 Rabatin JS, Lipkin M Jr, Rubin AS, Schachter A, Nathan M, Kalet A. A year of mentoring in academic medicine: Case report and qualitative analysis of fifteen hours of meetings between a junior and senior faculty member. J Gen Intern Med. 2004;19:569573.

22 Hewson MG. Clinical teaching in the ambulatory setting. J Gen Intern Med. 1992; 7:76-82.

23 Galicia AR, Klima RR, Date ES. Mentorship in physical medicine and rehabilitation residencies. Am J Phys Med Rehabil. 1997;76: 268-275.
24 Hauck F, Zyzanski S, Alemagno S, Medalie J. Patient perceptions of humanism in physicians: Effects on positive health behaviors. Fam Med. 1990;2:447-452.

25 Starr RA, Wagstaff NV. Implementing a surgical skills training program. Obstet Gynecol Clin North Am. 2006;33:247-258.

26 Jacobi M. Mentoring and undergraduate academic success: A literature review. Rev Educ Res. 1991;61:505-532.

27 Clawson JG. Mentoring in managerial careers. In: Derr CB, ed. Work, Family, and the Career: New Frontiers in Theory and Research. New York, NY: Praeger; 1980.

28 Barondess JA. On mentoring. J R Soc Med. 1997;90:347-349.

29 Maker VK, Curtis KD, Donnelly MB. Are you a surgical role model? Curr Surg. 2004;61: 111-115.

30 Zerzan JT, Hess R, Schur E, Phillips RS, Rigotti $\mathrm{N}$. Making the most of mentors: A guide for mentees. Acad Med. 2009;84:140-144.

31 Nakamura J, Shernoff D, Hooker C. Good Mentoring: Fostering Excellent Practice in Higher Education. San Francisco, Calif: Jossey-Bass; 2009.

32 Ragins BR, Scandura TA. Gender differences in expected outcomes of mentoring relationships. Acad Manage J. 1994;37:957971.

33 Ragins BR. Where do we go from here, and how do we get there? Methodological issues in conducting research on diversity and mentoring relationships. In: Murrell AJ, Crosby FJ, Ely RJ, eds. Mentoring Dilemmas: Developmental Relationships Within Multicultural Organizations. Mahwah, NJ: Lawrence Erlbaum Associates; 1999.

34 Spector PE. Using self-report questionnaires in $\mathrm{OB}$ research: $\mathrm{A}$ comment on the use of a controversial method. J Organ Behav. 1994; 15:385-392.

35 Howard GS. Why do people say nasty things about self-reports? J Organ Behav. 1994;15: 399-404.

36 Frey K, Edwards F, Altman K, Spahr N, Gorman RS. The "Collaborative Care" curriculum: An educational model addressing key ACGME core competencies in primary care residency training. Med Educ. 2003;37: 786-789. 